\title{
Mechanisms of Oxidative Damage in Multiple Sclerosis and a Cell Therapy Approach to Treatment
}

\author{
Jonathan Witherick, Alastair Wilkins, Neil Scolding, and Kevin Kemp \\ Multiple Sclerosis and Stem Cell Group, Institute of Clinical Neurosciences, School of Clinical Sciences, University of Bristol, \\ Bristol BS16 1LE, UK \\ Correspondence should be addressed to Neil Scolding, n.j.scolding@bristol.ac.uk
}

Received 1 September 2010; Accepted 10 November 2010

Academic Editor: Sreeram Ramagopalan

Copyright (๑) 2011 Jonathan Witherick et al. This is an open access article distributed under the Creative Commons Attribution License, which permits unrestricted use, distribution, and reproduction in any medium, provided the original work is properly cited.

\begin{abstract}
Although significant advances have recently been made in the understanding and treatment of multiple sclerosis, reduction of long-term disability remains a key goal. Evidence suggests that inflammation and oxidative stress within the central nervous system are major causes of ongoing tissue damage in the disease. Invading inflammatory cells, as well as resident central nervous system cells, release a number of reactive oxygen and nitrogen species which cause demyelination and axonal destruction, the pathological hallmarks of multiple sclerosis. Reduction in oxidative damage is an important therapeutic strategy to slow or halt disease processes. Many drugs in clinical practice or currently in trial target this mechanism. Cell-based therapies offer an alternative source of antioxidant capability. Classically thought of as being important for myelin or cell replacement in multiple sclerosis, stem cells may, however, have a more important role as providers of supporting factors or direct attenuators of the disease. In this paper we focus on the antioxidant properties of mesenchymal stem cells and discuss their potential importance as a cell-based therapy for multiple sclerosis.
\end{abstract}

\section{Introduction}

In recent years, clinical trials of stem cell therapies for neurological disorders have begun. Specifically in multiple sclerosis (MS), a number of trials studying the potential of bonemarrow-derived stem cell therapies have been published [13]. The initial experimental rationale was to regard stem cells as multipotential cells capable of differentiating into central nervous system cells able to replace lost or damaged cells in diseased tissue. Indeed, major research programmes of myelin repair are ongoing [4]. A further, and potentially more clinically applicable, function of stem cells is their ability to modulate disease processes. Mesenchymal stem cells (MSCs) have potent immune modulatory effects in experimental models [5]. Furthermore, MSCs are able to secrete a variety of substances that may attenuate disease processes or provide trophic support for the diseased nervous system $[6,7]$. In MS, oxidative stress is associated with significant damage to myelin and axons, which in turn leads to clinical symptoms [8]. A major research strategy for many years has been to develop therapies which reduce the damage caused by oxidative stress and thus reduce tissue injury. This paper will focus on stem cells, and specifically MSCs, as providers of antioxidant function for central nervous system cells.

\section{Mechanisms of Tissue Damage in MS and Experimental Models of CNS Inflammation}

2.1. The Immunology of Multiple Sclerosis. Multiple sclerosis has classically been thought of as a T-cell-dependent process associated with macrophage-mediated demyelination driven by myelin-specific autoantigens. Evidence for the central role of T cells includes the presence of Th1 (T helper) cytokines, receptors, and cells in the CSF, circulation, and lesions of MS patients [9-11]. Furthermore, $\mathrm{CD}^{+} \mathrm{T}$ cells polarized to Th1 phenotype play a central role in the animal model of MS, experimental autoimmune encephalomyelitis (EAE) [12]. In recent years, however, it has become clear that the 
immunological interplay in MS is much more complicated than first thought. Evidence countering the central role for $\mathrm{CD}^{+}{ }^{+} \mathrm{T}$ cells includes the fact that MHC class 1restricted $\mathrm{CD} 8^{+}$cells are the predominant cell type found in active MS lesions [13]; lymphocytes may not be present in early demyelinating lesions and perivascular inflammatory cuffs can occur in normal appearing white matter [14]. In addition, therapies such as anti-interleukin 12p40 that target $\mathrm{CD}^{+}{ }^{\mathrm{T}} \mathrm{T}$-cell function have proved ineffective in clinical trials [15]. These and other developments have led to the need for further interrogation of the underlying immunology of the condition and redirected efforts to focus on alternative cell types that may contribute to the pathogenesis of MS. Previously, unknown contributors to the disease process include Th17 cells (producing IL 17), B cells, CD $8^{+}$cells, and both $\mathrm{CD}^{+}$and $\mathrm{CD} 8^{+}$T-regulatory cells. Other effector populations include $\mathrm{CD}^{+} 6^{+}$natural killer cells, invariant NK cells, and stem cells [16]. There is also evidence for the role of humoral immunity in MS demonstrated by the presence of immunoglobulin on macrophages actively phagocytosing myelin [17], immunoglobulin and complement in degenerating myelin sheaths [18], and by the occurrence of plasma cells in plaques [19].

\subsection{Patterns of Tissue Injury in MS and Experimental} Demyelinating Models. Pathological changes noted in postmortem or (more rarely) biopsy tissue from patients suffering from MS have revealed some of the mechanisms of tissue damage. Several patterns of tissue injury have been demonstrated. Although only able to offer a "snap shot" of tissue damage, certain common themes, some specifically relating to oxidative damage, have emerged.

(i) Classical Actively Demyelinating Lesions. There is a broad spectrum of immunological findings with some lesions dominated by $\mathrm{T}$ cells and macrophages, whilst others are notable for their immunoglobulin and complement components. Experimental demyelinating lesions can be induced by cytotoxic $\mathrm{T}$ cells, autoantibody generation, and genetic abnormalities giving further indications of the variety of factors that may determine an in vivo lesion [20]. In EAE, inoculation with myelin components, including myelin basic protein (MBP), proteolipoprotein, myelin oligodendrocyte glycoprotein, myelinassociated glycoprotein, and S100 protein, elicits an immunological response mediated via $\mathrm{CD} 4^{+} \mathrm{MBP}-$ reactive $\mathrm{T}$ cells resulting in paralytic signs in the host organism. In EAE, demyelinating lesions require the presence of $\mathrm{T}$ cells, myelin autoantibodies, and complement activation though the relevance of this observation to MS is not fully established [21].

(ii) Slowly Expanding Lesions of Progressive MS. These are notable for the presence of a rim of activated microglia at their periphery with associated active demyelination. Macrophages containing myelin degradation products are not found within these lesions. T-cell infiltrates are located perivascularly but are not prevalent [22]. (iii) Cortical Demyelination. Cortical lesions are most commonly found in the deep sulcal structures in band-like subpial lesions [23]. Within these lesions, profound microglial activation can be viewed largely in the absence of lymphocytes [24]. The presence of a multitude of inflammatory cells within the meninges overlying these lesions has led some to hypothesise that they are driven by soluble factors released by the overlying cells [20].

(iv) Diffuse White Matter Injury. The so called "normal appearing white matter" (NAWM) (defined on magnetic resonance imaging) in fact demonstrates pathological abnormalities in MS patients, particularly in the progressive stages of the disease [25]. There is a predominance of $\mathrm{CD}^{+}$MHC class I-restricted $\mathrm{T}$ lymphocytes in a diffuse inflammatory infiltrate found particularly in the perivascular space. There is widespread activation of microglia expressing footprint activation antigens of radical production, and microglial activation is closely associated with diffuse axonal injury/loss. There is no doubt that some Wallerian degeneration of axons occurs following focal demyelinating lesions, but within the NAWM there is a greater degree of inflammation and microglial activation than would be expected with Wallerian degeneration alone [20]. Many of the mechanisms leading to diffuse injury in NAWM are poorly understood; within activated microglia, frequently found in NAWM, there is expression of type-II nitric oxide synthases suggesting that oxygen and nitric oxide radicals are involved in the process; nitric oxide/oxygen free radicals inhibit enzymes of the respiratory chain causing mitochondrial dysfunction [26] which may be an important factor driving axon dysfunction; the size-dependent axonal loss in NAWM suggests energy deficiency which may also play an important role in the progressive axon loss characterising the latter stages of the disease [27].

2.3. Oxidative and Nitrative Stress. Reactive oxygen species (ROS) and reactive nitrogen species (RNS) are generated as part of normal cellular physiology. However, if there is overproduction of ROS or a failure of antioxidant mechanisms, these species can cause damage to lipids, proteins, and nucleic acids and may lead to cell death. CNS neurones are constantly exposed to low levels of these oxidative/nitrative species which can easily be dealt with by inherent repair and protection mechanisms. In the inflammatory state, however, these defences can become overwhelmed leading to oxidative/nitrative stress and damage to the basic structural and functional elements of the cells. Reactive oxygen and nitrogen species include superoxide ions, hydrogen peroxide, nitric oxide, and peroxynitrite, all of which are produced as part of the inflammatory response and have a potential role in tissue damage in multiple sclerosis. High levels of NO, peroxynitrite, and superoxide have all been demonstrated in spinal fluid from patients with MS [28]. 


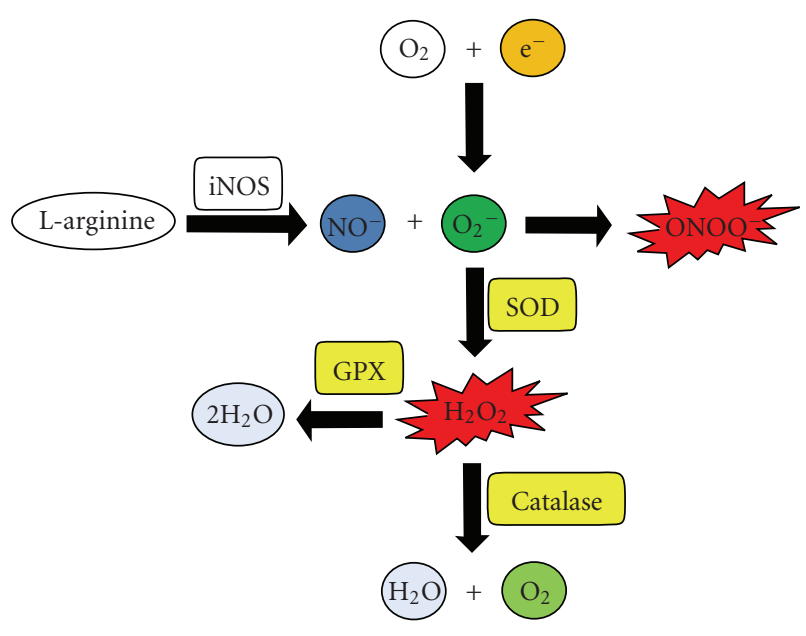

Figure 1: Cellular detoxification of reactive oxygen and nitrative species. Oxygen is reduced to superoxide $\left(\mathrm{O}_{2}^{-}\right)$during inflammation, and nitric oxide $\left(\mathrm{NO}^{-}\right)$is generated by the action of inflammatory nitric oxide synthase (iNOS) on L-arginine. In the absence of detoxifying enzymes, $\mathrm{NO}^{-}$and $\mathrm{O}_{2}^{-}$react to produce the highly toxic peroxynitrite $\left(\mathrm{ONOO}^{-}\right)$. Superoxide dismutase (SOD) competes for the superoxide anion and dismutes it to form hydrogen peroxide $\left(\mathrm{H}_{2} \mathrm{O}_{2}\right)$ which can then be removed by the enzymes catalase and glutathione peroxidase (GPX).

There are several reasons why the CNS is particularly vulnerable to oxidative damage. These include the fact that brain tissue is very active in oxidative metabolism leading to relatively high levels of intracellular superoxides: the limited ability of the CNS to engage in anaerobic respiration resulting in high levels of superoxides in a hypoxic environment [29]; cellular features predisposing to oxidative damage within the oligodendrocyte population including low levels of antioxidant defences, membrane elaborations, and high iron content; the composition of myelin as a preferential target of ROS due to high protein : lipid ratio [30].

2.3.1. Reactive Nitrogen Species. Nitric oxide (NO) is produced in the nervous system in response to inflammation through the induction of inflammatory nitric oxide synthase (iNOS). It has been demonstrated that there is increased iNOS production, and by implication NO species, in the CNS of animals with EAE, [31]. There is also evidence of increased proinflammatory cytokine production in MS, and by extension NO [9]. Further indirect evidence of NO production includes the following: TNF $\alpha$ and IFN $\gamma$ have been identified in astrocytes within both CNS lesions and CSF white blood cells of patients with MS [32]; higher levels of NO have been demonstrated within the peripheral monocytes of patients with MS compared with control subjects [33]; nitrite and nitrate levels are elevated in the CSF of patients with MS [34]. Direct evidence includes the fact that iNOS mRNA has been identified in MS plaques [35] with evidence that macrophages, astrocytes, and microglia within active lesions express high levels of iNOS and endothelial NOS [36]. There is also evidence for the presence of reactive nitrogen species in MS through nitrotyrosine, a marker of the presence of peroxynitrite, which is found in the diseased brain particularly in areas of demyelination and inflammation [37].

Reactive nitrogen species have a wide variety of effects on cells through the modification of protein structure and function: they inhibit several enzymes involved in respiration thereby disrupting mitochondrial function and reducing ATP content as demonstrated in neurons exposed to NO [32]; NO is known to affect several of the enzymes involved in oxidative defence including catalase [38]; it has been hypothesised that oxidation also results in the production of epitopes which may provoke autoimmune responses [39]; peroxynitrite can lead to cell death through a number of mechanisms including affecting cell signalling and through DNA breakdown [40]; NO can also deaminate DNA [41] and inhibit repair mechanisms [42]. Both reactive nitrogen and oxygen species also affect lipid peroxidation and consequently membrane function/permeability, which has implications for the function of embedded proteins within the lipid bilayer [43].

Oligodendrocytes show particular susceptibility to NO species and can even be lysed by the levels of NO produced by activated microglial cells. Experiments have shown that this lysis can be prevented in coculture by the addition of antagonists of NO production [44].

High levels of phosphorylation within axon neurofilaments protect against proteolysis. Dephosphorylation renders the axons more susceptible to proteolytic damage and axonal degeneration [45]. It has been shown that inflammatory agents, such as nitric oxide (NO), reduce neurofilament phosphorylation levels and thereby facilitate axon destruction. It is also known that inflammation causes conduction block and has been demonstrated in vivo that $\mathrm{NO} /$ derivatives can block conduction in both central and peripheral axons and that demyelinated axons are particularly vulnerable to NO-mediated block [46].

2.3.2. Reactive Oxygen Species. Extensive evidence implies increased ROS production in inflammatory demyelinating diseases. Human microglia are one of the most potent producers of superoxide [47], and it is known that during inflammatory demyelinating disease cells such as these are recruited to lesions within the CNS. Neurons also produce ROS in response to electrical activity following eicosanoid production driven by calcium cellular influx [48]. Direct evidence of lipid peroxidation has been demonstrated in postmortem brain tissue with findings pointing to a pivotal role in early plaque evolution [49]. There is also evidence for increased ROS production in EAE with macrophages and microglial cells exhibiting high levels compared with controls [50] and for higher levels of superoxide throughout affected brain areas [51]. It has also been noted that peroxynitrite is formed very early in the course of EAE and correlates with disease activity [52].

Oligodendrocytes are susceptible experimentally to ROSmediated damage at levels which do not affect astrocytes or macrophages [53]. The high levels of iron found in oligodendrocytes, reacting with hydrogen peroxide and 


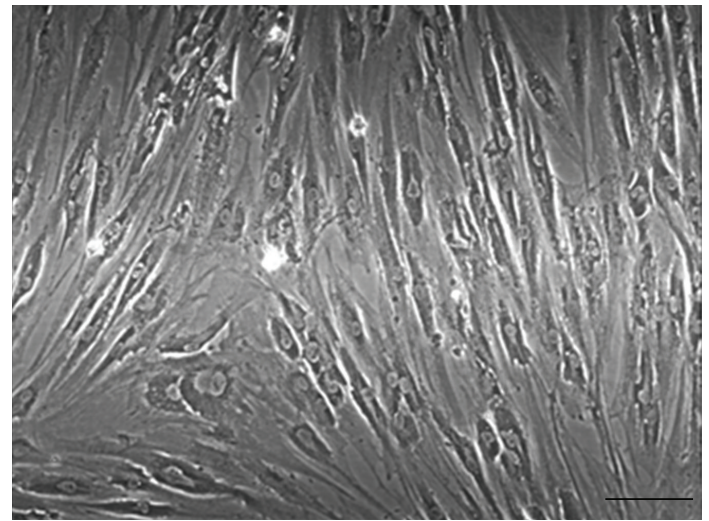

(a)

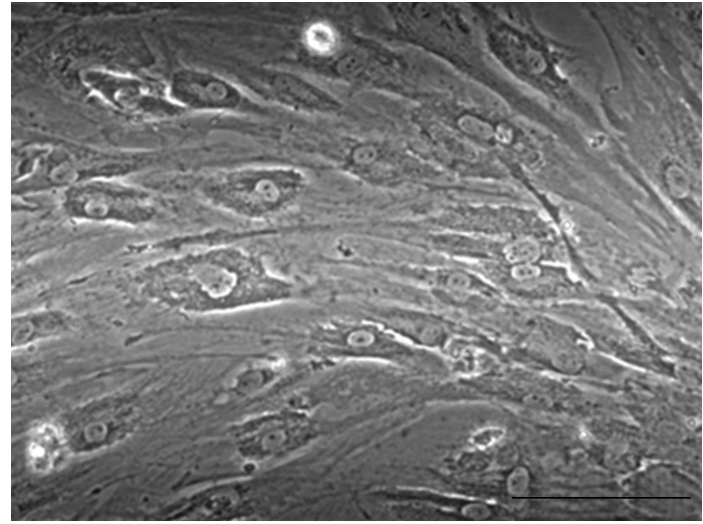

(b)

Figure 2: Human bone-marrow-derived mesenchymal stem cells in culture (scale bar = 100 microns).

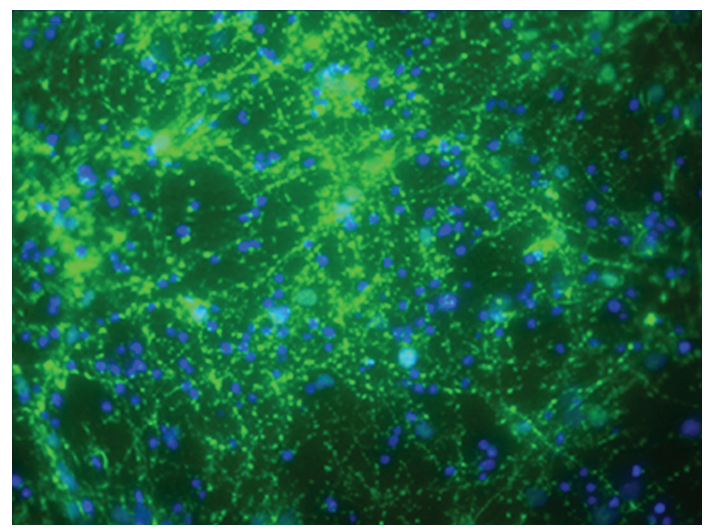

(a)

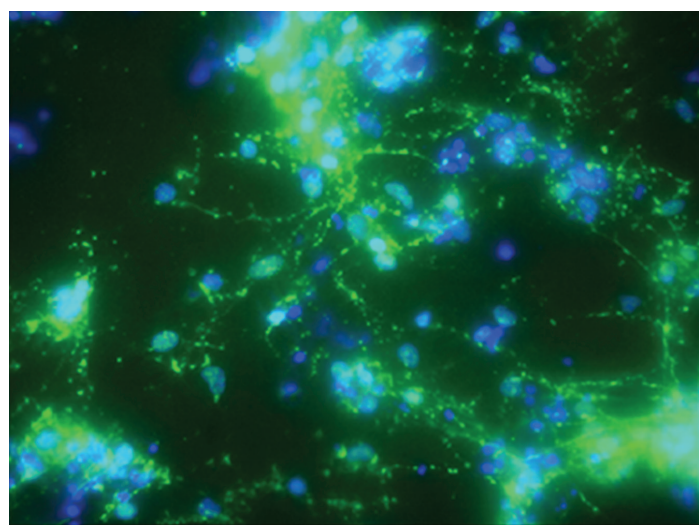

(b)

FIGURE 3: Nitric oxide promotes axonal injury to cerebellar neurones in vitro. Immunofluorescent images depicting cerebellar axonal morphology (a) pre- and (b) posttreatment with $0.1 \mathrm{mM} \mathrm{NO}$. Green: axonal marker SMI 312. Blue: DAPI nuclear stain.

leading to the formation of the highly toxic peroxynitrite, may explain this susceptibility. In addition, low oligodendrocyte levels of glutathione, the failure of expression of Mn-SOD, and low levels of metallothionein, all important antioxidants, may contribute [54-56]. Hydrogen peroxide is produced in peroxisomes which are particularly abundant in oligodendrocytes during the period of active remyelination, contributing to the failure of long-term repair of myelin and the axon loss associated with the progressive stages of the disease. Furthermore, preoligodendrocytes appear to be significantly more sensitive to oxidative stress compared to mature oligodendroctes [57] providing further barriers to repair and remyelination. ROS also have direct effects on the lipid and protein components of myelin, directly through peroxidation and indirectly through the production of matrix metalloproteinases which have been shown to degrade myelin basic protein.

2.3.3. Detoxification of Reactive Oxygen and Nitrogen Species. Cells possess a diverse array of defence mechanisms to reduce potentially harmful build-up of ROS, specifically a number of antioxidant enzymes including superoxide dismutase, catalase, glutathione peroxidase, and glutathione reductase (Figure 1). The balance between ROS/RNS and detoxifying enzymes within inflamed tissue may be crucially important in determining the extent of cellular damage and tissue injury.

The cause of axonal degeneration in secondary progressive disease is unknown, but recent evidence has suggested a role for central nervous system peroxisomes in axonal maintenance [58]. Peroxisomes are cellular organelles which are involved in a number of anabolic and catabolic reactions and may have an important role in the detoxification of inflammatory compounds such as ROS. Both SOD and catalase are produced by peroxisomes, and catalase is specific to peroxisomes. Inherited abnormalities in peroxisomal function cause a variety of neurological disorders, including $\mathrm{X}$-linked adrenoleucodystrophy and adrenomyeloneuropathy, which share many clinical, radiological, and neuropathological features with multiple sclerosis [59]. Furthermore, defects in peroxisomal function within the central nervous 
system have been implicated in experimental models of neuroinflammatory and neurodegenerative disease [60]. Thus, peroxisomes may have vital functions in multiple sclerosis of limiting tissue damage. We have previously shown that nitric oxide causes significant axonal and neuronal damage in cell culture models (Figure 3) [61] and that the addition of recombinant SOD to cultures protects cerebellar neurons from nitric-oxide-mediated injury $[62,63]$.

\section{Cell-Based Approaches to Combat Oxidative Damage in Multiple Sclerosis}

A number of different cell-based approaches to repair and protect against tissue damage in MS have been postulated and are the subject of intense research. Examples include haematopoietic stem cells which have been used in an immune-reprogramming capacity and neural stem cells which are predominantly being explored for their regenerative potential. Meanwhile, mesenchymal stem cells (MSCs) (Figure 2) have emerged as promising candidates in the protection of neurones against the oxidative damage encountered in MS. Here we describe the biology of MSCs and the antioxidant properties which may have future relevance to the treatment of the disease.

3.1. Mesenchymal Stem Cells. The potential therapeutic applications of MSCs for neurological disorders have generated great interest. To date, human MSC transplantation has been shown to improve outcome in a variety of animal models of neurological disease including that of experimental autoimmune encephalomyelitis, stroke, amyotrophic lateral sclerosis, Krabbe's disease, and spinal cord injury [64-77]. Pilot translational studies of MSC therapy have also commenced in stroke [78], multiple system atrophy [79], amyotrophic lateral sclerosis [80], metachromatic leukodystrophy, and Hurlers syndrome [81], as well as in multiple sclerosis [82]. Administration of MSC is an attractive therapeutic option in these disorders as MSCs are easily isolated from various anatomical sources, have versatile growth and differentiation potential, and their immunosuppressive properties make it probable that allogeneic as well as autologous cell therapy could be considered. This is of importance since in clinical therapies the use of an allogeneic source for cellular therapy is likely to be more convenient and feasible than an autologous population which would take weeks to prepare [83]. Despite having a favourable safety profile in comparison with some other types of stem cells, there are undoubtedly risks associated with MSC treatments which should not go unexplored. The use of an allogenic MSC bank, for example, would carry with it the risks of chromosomal abnormalities associated with longterm cell culture and development of therapies will require the provision of careful and considered safety studies and protocols.

MSCs were first identified in 1966 in studies by Friedenstein et al., who isolated bone-/cartilage-forming progenitor cells from rat bone marrow cells with fibroblast-like morphology [84]. Since this discovery, the most studied and accessible source of MSCs has been the bone marrow, although MSCs have been isolated from a number of tissues including the liver, foetal blood, cord blood, and amniotic fluid [85-93]. Unlike the haematopoietic stem cells and their progeny, cultured MSCs express a number of nonspecific surface markers, none of which, individually or in combination, have been shown to achieve high levels of MSC isolation and enrichment [94-98]. Within the bone marrow, MSCs comprise $0.001-0.1 \%$ of the total population of nucleated cells [85]. MSCs may be considered multi-potent stem cells that have the ability to differentiate down both mesenchymal and nonmesenchymal lineages. Human MSCs contribute to the regeneration of mesenchymal tissues such as bone, cartilage, muscle, ligament, tendon, adipose, and stroma [85] and can also give rise to cells with ectodermal and endodermal phenotypes [98-104].

Research suggests that transplantation of MSCs has the potential to be an effective treatment for neurodegenerative disorders through a multitude of different mechanisms including replacement of lost cells by differentiation into functional neural tissue, modulation of the immune system to prevent further neurodegeneration, and provision of trophic support for the diseased nervous system [105]. Bone-marrow-derived MSCs are able to evade the allogeneic immune system, as well as suppress immune responses directed against third-party cells following intravenous infusion [106-109]. In addition, when infused into the circulation, MSCs have the capacity to migrate specifically to sites of brain injury, thus targeting sites for neural repair [7577]. Although MSCs display a plethora of neuroprotective and regenerative properties, increasing evidence implies that the major mechanistic neuroprotective role of bone-marrowderived MSCs is their capacity to secrete a diverse range of potentially neuroprotective factors including antioxidants $[5,6,105,110-112]$. With many antioxidant drugs emerging as potential therapeutic agents for neurodegenerative disorders $[113,114]$, these findings emphasise the potential for bone-marrow-derived MSCs as therapeutic agents for CNS neurodegenerative disorders, especially disorders in which oxidative damage is a key aetiological component.

3.2. Antioxidant Properties of Mesenchymal Stem Cells. MSCs have direct antioxidant activity that is conducive to neuroprotection both in vivo and in vitro $[5,7]$. In vitro studies have shown that MSC-conditioned media can confer a neuroprotective effect against oxidative insult to both primary cortical and cerebellar neurons, and also neuroblastoma cell lines [5-7, 63]. Evidence suggests that one method by which MSCs exert a neuroprotective effect against oxidative stress is through the modulation of signalling pathways involved in antioxidant and stress-related processes. Nitric oxide, whilst performing many physiological roles at low levels, has been shown to induce apoptosis in a variety of cultured peripheral and central neurons and be involved in degeneration during central nervous system inflammation $[115,116]$. It has been established that these effects are mediated through the p38 MAP kinase pathway [61]. Secreted protein factors, including neurotrophic factors and cytokines, are thought to have the 
ability to inhibit death-inducing pathways and also activate cell survival pathways $[117,118]$. MSCs have been shown to protect neurons against toxic insults via modulation of both the $\mathrm{PI}_{3}$ kinase/Akt and MAP kinase pathways [7].

Another mechanism by which MSCs can exert a direct antioxidant effect is through the secretion of antioxidant molecules. We have recently shown that bone-marrowderived MSCs secrete the extracellular antioxidant molecule superoxide dismutase 3 (SOD3) [7, 63]. The superoxide dismutase family member SOD3 is the only antioxidant enzyme that scavenges superoxide in the extracellular compartment [119] and limits the formation of strong neurotoxic oxidants including both the hydroxyl radical and peroxynitrite in the extracellular space. It has been demonstrated in a variety of studies that SOD3 can attenuate tissue damage and inflammation [120-128]; in addition, SOD3 secretion by human MSCs has been shown to provide direct neuroprotection in cerebellar neurons exposed to nitric oxide and activated microglia $[7,63]$. Experiments show that SOD3 secretion by human bone-marrow-derived MSCs is regulated synergistically by the inflammatory cytokines TNF $\alpha$ and IFN $\gamma$ [63]. Both TNF $\alpha$ and IFN $\gamma$ are important mediators of the immune system and inflammatory processes in the CNS and are therefore present in the diseased brain. In EAE and other central nervous system inflammatory disorders, both IFN $\gamma$ and TNF $\alpha$ are upregulated and are critically involved in the initiation and amplification of the local immune response [129]. These cytokines also enhance the secretion of the superoxide ions by a variety of immune and nonimmune cells [130-133]. In summary, SOD3 secretion by MSCs is a potentially valuable and regulatable therapeutic antiinflammatory property that may be of relevance to treatment strategies for inflammatory disease of the CNS.

Several studies have looked at the effects of transplanted MSCs on both the clinical course and immunopathology of EAE. MSC transplantation confers significant therapeutic capacity to modulate autoimmune processes, resulting in significant reductions in demyelination and lesion size within the CNS and also reductions in the number of cellular infiltrates in the brains of the host organism $[68,69$, 134-137]. Inflammatory processes within the CNS involve activated microglia, astrocytes, macrophages, and lymphocytes, releasing a plethora of anti- and proinflammatory cytokines [138]. Evidence from both in vitro and in vivo studies suggests that MSCs have the ability to inhibit microglial activation and therefore attenuate inflammation [139-142]. It has also been shown that MSCs are capable of significantly decreasing inducible nitric oxide synthase (iNOS) expression within microglia [140], thus enhancing their antioxidative effect. Further supporting evidence has recently shown that MSCs inhibit molecules associated with neuronal damage and display a variety of antioxidant effects when administered to EAE mice [5].

\section{Conclusions}

MSCs possess a diverse range of properties making them attractive candidates for cell-based therapies. In particular, antioxidant functions may be utilised as a strategy to reduce inflammation-driven oxidative stress. Cell-based therapies for MS are currently in development, and the diverse modes of action of stem cells make them attractive candidates. Further work to enhance delivery and targeting of cells, plus optimising and regulating their antioxidant properties, is required, but stem cell therapies for MS may form an important part of the therapeutic armoury for the disease in years to come.

\section{References}

[1] B. Yamout, R. Hourani, H. Salti et al., "Bone marrow mesenchymal stem cell transplantation in patients with multiple sclerosis: a pilot study," Journal of Neuroimmunology, vol. 227, no. 1-2, pp. 185-189, 2010.

[2] C. M. Rice, E. A. Mallam, A. L. Whone et al., "Safey and feasibility of autologous bone marrow cellular therapy in relapsing-progressive multiple sclerosis," Clinical Pharmacology and Therapeutics, vol. 87, no. 6, pp. 679-685, 2010.

[3] D. Karussis, C. Karageorgiou, A. Vaknin-Dembinsky et al., "Safety and immunological effects of mesenchymal stem cell transplantation in patients with multiple sclerosis and amyotrophic lateral sclerosis," Archives of Neurology, vol. 67, no. 10, pp. 1187-1194, 2010.

[4] R. J. M. Franklin and C. Ffrench-Constant, "Remyelination in the CNS: from biology to therapy," Nature Reviews Neuroscience, vol. 9, no. 11, pp. 839-855, 2008.

[5] C. Lanza, S. Morando, A. Voci et al., "Neuroprotective mesenchymal stem cells are endowed with a potent antioxidant effect in vivo," Journal of Neurochemistry, vol. 110, no. 5, pp. 1674-1684, 2009.

[6] A. Wilkins, K. Kemp, M. Ginty, K. Hares, E. Mallam, and N. Scolding, "Human bone marrow-derived mesenchymal stem cells secrete brain-derived neurotrophic factor which promotes neuronal survival in vitro," Stem Cell Research, vol. 3, no. 1, pp. 63-70, 2009.

[7] K. Kemp, K. Hares, E. Mallam, K. J. Heesom, N. Scolding, and A. Wilkins, "Mesenchymal stem cell-secreted superoxide dismutase promotes cerebellar neuronal survival," Journal of Neurochemistry, vol. 114, no. 6, pp. 1569-1580, 2010.

[8] J. van Horssen, M. E. Witte, G. Schreibelt, and H. E. de Vries, "Radical changes in multiple sclerosis pathogenesis," Biochimica et Biophysica Acta (2010). In press.

[9] J. E. Merrill, "Proinflammatory and antiinflammatory cytokines in multiple sclerosis and central nervous system acquired immunodeficiency syndrome," Journal of Immunotherapy, vol. 12, no. 3, pp. 167-170, 1992.

[10] B. Cannella and C. S. Raine, "The adhesion molecule and cytokine profile of multiple sclerosis lesions," Annals of Neurology, vol. 37, no. 4, pp. 424-435, 1995.

[11] V. Navikas and H. Link, "Review: cytokines and the pathogenesis of multiple sclerosis," Journal of Neuroscience Research, vol. 45, no. 4, pp. 322-333, 1996.

[12] A. Khoruts, S. D. Miller, and M. K. Jenkins, "Neuroantigenspecific Th2 cells are inefficient suppressors of experimental autoimmune encephalomyelitis induced by effector Th1 cells," Journal of Immunology, vol. 155, no. 10, pp. 5011-5017, 1995.

[13] H. Babbe, A. Roers, A. Waisman et al., "Clonal expansions of CD8 $\mathrm{T}$ cells dominate the $\mathrm{T}$ cell infiltrate in active multiple sclerosis lesions as shown by micromanipulation and single 
cell polymerase chain reaction," Journal of Experimental Medicine, vol. 192, no. 3, pp. 393-404, 2000.

[14] M. H. Barnett and I. Sutton, "The pathology of multiple sclerosis: a paradigm shift," Current Opinion in Neurology, vol. 19, no. 3, pp. 242-247, 2006.

[15] B. M. Segal, C. S. Constantinescu, A. Raychaudhuri, L. Kim, R. Fidelus-Gort, and L. H. Kasper, "Repeated subcutaneous injections of IL12/23 p40 neutralising antibody, ustekinumab, in patients with relapsing-remitting multiple sclerosis: a phase II, double-blind, placebo-controlled, randomised, dose-ranging study," The Lancet Neurology, vol. 7, no. 9, pp. 796-804, 2008.

[16] L. H. Kasper and J. Shoemaker, "Multiple sclerosis immunology: the healthy immune system vs the MS immune system," Neurology, vol. 74, supplement 1, pp. S2-S8, 2010.

[17] J. W. Prineas and J. S. Graham, "Multiple sclerosis: capping of surface immunoglobulin $\mathrm{G}$ on macrophages engaged in myelin breakdown," Annals of Neurology, vol. 10, no. 2, pp. 149-158, 1981.

[18] M. K. Storch, S. Piddlesden, M. Haltia, M. Iivanainen, P. Morgan, and H. Lassmann, "Multiple sclerosis: in situ evidence for antibody- and complement-mediated demyelination," Annals of Neurology, vol. 43, no. 4, pp. 465-471, 1998.

[19] J. W. Prineas, "Multiple sclerosis: presence of lymphatic capillaries and lymphoid tissue in the brain and spinal cord," Science, vol. 203, no. 4385, pp. 1123-1125, 1979.

[20] H. Lassmann, W. Brück, and C. F. Lucchinetti, "The immunopathology of multiple sclerosis: an overview," Brain Pathology, vol. 17, no. 2, pp. 210-218, 2007.

[21] D. Merkler, T. Ernsting, M. Kerschensteiner, W. Brück, and C. Stadelmann, "A new focal EAE model of cortical demyelination: multiple sclerosis-like lesions with rapid resolution of inflammation and extensive remyelination," Brain, vol. 129, no. 8, pp. 1972-1983, 2006.

[22] J. W. Prineas, E. E. Kwon, E. S. Cho et al., "Immunopathology of secondary-progressive multiple sclerosis," Annals of Neurology, vol. 50, no. 5, pp. 646-657, 2001.

[23] J. W. Peterson, L. Bö, S. Mörk, A. Chang, and B. D. Trapp, "Transected neurites, apoptotic neurons, and reduced inflammation in cortical multiple sclerosis lesions," Annals of Neurology, vol. 50, no. 3, pp. 389-400, 2001.

[24] L. Bø, C. A. Vedeler, H. Nyland, B. D. Trapp, and S. J. Mørk, "Intracortical multiple sclerosis lesions are not associated with increased lymphocyte infiltration," Multiple Sclerosis, vol. 9, no. 4, pp. 323-331, 2003.

[25] A. Kutzelnigg, C. F. Lucchinetti, C. Stadelmann et al., "Cortical demyelination and diffuse white matter injury in multiple sclerosis," Brain, vol. 128, no. 11, pp. 2705-2712, 2005.

[26] J. P. Bolaños, A. Almeida, V. Stewart et al., "Nitric oxidemediated mitochondrial damage in the brain: mechanisms and implications for neurodegenerative diseases," Journal of Neurochemistry, vol. 68, no. 6, pp. 2227-2240, 1997.

[27] P. K. Stys, "General mechanisms of axonal damage and its prevention," Journal of the Neurological Sciences, vol. 233, no. 1-2, pp. 3-13, 2005.

[28] V. Calabrese, G. Scapagnini, A. Ravagna et al., "Nitric oxide synthase is present in the cerebrospinal fluid of patients with active multiple sclerosis and is associated with increases in cerebrospinal fluid protein nitrotyrosine and Snitrosothiols and with changes in glutathione levels," Journal of Neuroscience Research, vol. 70, no. 4, pp. 580-587, 2002.
[29] A. Bast, G. R. M. M. Haenen, and C. J. A. Doelman, "Oxidants and antioxidants: state of the art," American Journal of Medicine, vol. 91, no. 3C, pp. 2S-13S, 1991.

[30] E. R. Bongarzone, J. M. Pasquini, and E. F. Soto, "Oxidative damage to proteins and lipids of CNS myelin produced by in vitro generated reactive oxygen species," Journal of Neuroscience Research, vol. 41, no. 2, pp. 213-221, 1995.

[31] R. F. Lin, T. S. Lin, R. G. Tilton, and A. H. Cross, "Nitric oxide localized to spinal cords of mice with experimental allergic encephalomyelitis: an electron paramagnetic resonance study," Journal of Experimental Medicine, vol. 178, no. 2, pp. 643-648, 1993.

[32] K. J. Smith, R. Kapoor, and P. A. Felts, "Demyelination: the role of reactive oxygen and nitrogen species," Brain Pathology, vol. 9, no. 1, pp. 69-92, 1999.

[33] P. Sarchielli, A. Orlacchio, F. Vicinanza et al., "Cytokine secretion and nitric oxide production by mononuclear cells of patients with multiple sclerosis," Journal of Neuroimmunology, vol. 80, no. 1-2, pp. 76-86, 1997.

[34] G. Giovannoni, "Cerebrospinal fluid and serum nitric oxide metabolites in patients with multiple sclerosis," Multiple Sclerosis, vol. 4, no. 1, pp. 27-30, 1998.

[35] L. Bö, T. M. Dawson, S. Wesselingh et al., "Induction of nitric oxide synthase in demyelinating regions of multiple sclerosis brains," Annals of Neurology, vol. 36, no. 5, pp. 778-786, 1994.

[36] C. J. A. De Groot, S. R. Ruuls, J. W. M. Theeuwes, C. D. Dijkstra, and P. Van Der Valk, "Immunocytochemical characterization of the expression of inducible and constitutive isoforms of nitric oxide synthase in demyelinating multiple sclerosis lesions," Journal of Neuropathology and Experimental Neurology, vol. 56, no. 1, pp. 10-20, 1997.

[37] A. H. Cross, P. T. Manning, R. M. Keeling, R. E. Schmidt, and T. P. Misko, "Peroxynitrite formation within the central nervous system in active multiple sclerosis," Journal of Neuroimmunology, vol. 88, no. 1-2, pp. 45-56, 1998.

[38] K. Dobashi, K. Pahan, A. Chahal, and I. Singh, "Modulation of endogenous antioxidant enzymes by nitric oxide in rat C6 glial cells," Journal of Neurochemistry, vol. 68, no. 5, pp. 18961903, 1997.

[39] A. I. Boullerne, K. G. Petry, M. Meynard, and M. Geffard, "Indirect evidence for nitric oxide involvement in multiple sclerosis by characterization of circulating antibodies directed against conjugated S-nitrosocysteine," Journal of Neuroimmunology, vol. 60, no. 1-2, pp. 117-124, 1995.

[40] C. Szabó, "DNA strand breakage and activation of polyADP ribosyltransferase: a cytotoxic pathway triggered by peroxynitrite," Free Radical Biology and Medicine, vol. 21, no. 6, pp. 855-869, 1996.

[41] D. A. Wink, K. S. Kasprzak, C. M. Maragos et al., "DNA deaminating ability and genotoxicity of nitric oxide and its progenitors," Science, vol. 254, no. 5034, pp. 1001-1003, 1991.

[42] M. Graziewicz, D. A. Wink, and F. Laval, "Nitric oxide inhibits DNA ligase activity: potential mechanisms for NOmediated DNA damage," Carcinogenesis, vol. 17, no. 11, pp. 2501-2505, 1996.

[43] R. Radi, J. S. Beckman, K. M. Bush, and B. A. Freeman, "Peroxynitrite-induced membrane lipid peroxidation: the cytotoxic potential of superoxide and nitric oxide," Archives of Biochemistry and Biophysics, vol. 288, no. 2, pp. 481-487, 1991.

[44] J. E. Merrill, L. J. Ignarro, M. P. Sherman, J. Melinek, and T. E. Lane, "Microglial cell cytotoxicity of oligodendrocytes is 
mediated through nitric oxide," Journal of Immunology, vol. 151, no. 4, pp. 2132-2141, 1993.

[45] M. E. Goldstein, N. H. Sternberger, and L. A. Sternberger, "Phosphorylation protects neurofilaments against proteolysis," Journal of Neuroimmunology, vol. 14, no. 2, pp. 149-160, 1987.

[46] E. J. Redford, R. Kapoor, and K. J. Smith, "Nitric oxide donors reversibly block axonal conduction: demyelinated axons are especially susceptible," Brain, vol. 120, no. 12, pp. 2149-2157, 1997.

[47] C. Colton, S. Wilt, D. Gilbert, O. Chernyshev, J. Snell, and M. Dubois-Dalcq, "Species differences in the generation of reactive oxygen species by microglia," Molecular and Chemical Neuropathology, vol. 28, no. 1-3, pp. 15-20, 1996.

[48] S. C. Bondy and C. P. LeBel, "The relationship between excitotoxicity and oxidative stress in the central nervous system," Free Radical Biology and Medicine, vol. 14, no. 6, pp. 633-642, 1993.

[49] J. Newcombe, H. Li, and M. L. Cuzner, "Low density lipoprotein uptake by macrophages in multiple sclerosis plaques: implications for pathogenesis," Neuropathology and Applied Neurobiology, vol. 20, no. 2, pp. 152-162, 1994.

[50] S. R. Ruuls, J. Bauer, K. Sontrop, I. Huitinga, B. A. 'T Hart, and C. D. Dijkstra, "Reactive oxygen species are involved in the pathogenesis of experimental allergic encephalomyelitis in Lewis rats," Journal of Neuroimmunology, vol. 56, no. 2, pp. 207-217, 1995.

[51] G. S. Scott, K. Ivor Williams, and C. Bolton, "Reactive oxygen species in experimental allergic encephalomyelitis," Biochemical Society Transactions, vol. 25, no. 2, p. 166S, 1997.

[52] R. C. van der Veen, D. R. Hinton, F. Incardonna, and F. M. Hofman, "Extensive peroxynitrite activity during progressive stages of central nervous system inflammation," Journal of Neuroimmunology, vol. 77, no. 1, pp. 1-7, 1997.

[53] C. Griot, M. Vandevelde, A. Richard, E. Peterhans, and R. Stocker, "Selective degeneration of oligodendrocytes mediated by reactive oxygen species," Free Radical Research Communications, vol. 11, no. 4-5, pp. 181-193, 1990.

[54] K. Nakajima and K. Suzuki, "Immunochemical detection of metallothionein in brain," Neurochemistry International, vol. 27, no. 1, pp. 73-87, 1995.

[55] E. Pinteaux, M. Perraut, and G. Tholey, "Distribution of mitochondrial manganese superoxide dismutase among rat glial cells in culture," Glia, vol. 22, no. 4, pp. 408-414, 1998.

[56] S. K. Thorburne and B. H. J. Juurlink, "Low glutathione and high iron govern the susceptibility of oligodendroglial precursors to oxidative stress," Journal of Neurochemistry, vol. 67, no. 3, pp. 1014-1022, 1996.

[57] S. A. Back, X. Gan, Y. Li, P. A. Rosenberg, and J. J. Volpe, "Maturation-dependent vulnerability of oligodendrocytes to oxidative stress-induced death caused by glutathione depletion," Journal of Neuroscience, vol. 18, no. 16, pp. 62416253, 1998.

[58] C. M. Kassmann, C. Lappe-Siefke, M. Baes et al., "Axonal loss and neuroinflammation caused by peroxisome-deficient oligodendrocytes," Nature Genetics, vol. 39, no. 8, pp. 969976, 2007.

[59] H. W. Moser, A. Mahmood, and G. V. Raymond, "X-linked adrenoleukodystrophy," Nature Clinical Practice Neurology, vol. 3, no. 3, pp. 140-151, 2007.

[60] L. Hulshagen, O. Krysko, A. Bottelbergs et al., "Absence of functional peroxisomes from mouse CNS causes dysmyelination and axon degeneration," Journal of Neuroscience, vol. 28, no. 15, pp. 4015-4027, 2008.
[61] A. Wilkins and A. Compston, "Trophic factors attenuate nitric oxide mediated neuronal and axonal injury in vitro: roles and interactions of mitogen-activated protein kinase signalling pathways," Journal of Neurochemistry, vol. 92, no. 6, pp. 1487-1496, 2005.

[62] K. Kemp, K. Hares, E. Mallam, K. J. Heesom, N. Scolding, and A. Wilkins, "Mesenchymal stem cell-secreted superoxide dismutase promotes cerebellar neuronal survival," Journal of Neurochemistry, vol. 114, no. 6, pp. 1569-1580, 2010.

[63] K. Kemp, E. Gray, E. Mallam, N. Scolding, and A. Wilkins, "Inflammatory cytokine induced regulation of superoxide dismutase 3 expression by human mesenchymal stem cells," Stem Cell Reviews and Reports, vol. 6, no. 4, pp. 548-559, 2010.

[64] C. P. Zhao, C. Zhang, S. N. Zhou et al., "Human mesenchymal stromal cells ameliorate the phenotype of SOD1-G93A ALS mice," Cytotherapy, vol. 9, no. 5, pp. 414-426, 2007.

[65] M. Koda, S. Okada, T. Nakayama et al., "Hematopoietic stem cell and marrow stromal cell for spinal cord injury in mice," NeuroReport, vol. 16, no. 16, pp. 1763-1767, 2005.

[66] B. T. Himes, B. Neuhuber, C. Coleman et al., "Recovery of function following grafting of human bone marrow-derived stromal cells into the injured spinal cord," Neurorehabilitation and Neural Repair, vol. 20, no. 2, pp. 278-296, 2006.

[67] J. Zhang, YI. Li, J. Chen et al., "Expression of insulin-like growth factor 1 and receptor in ischemic rats treated with human marrow stromal cells," Brain Research, vol. 1030, no. 1, pp. 19-27, 2004.

[68] J. Zhang, YI. Li, M. Lu et al., "Bone marrow stromal cells reduce axonal loss in experimental autoimmune encephalomyelitis mice," Journal of Neuroscience Research, vol. 84, no. 3, pp. 587-595, 2006.

[69] D. Gordon, G. Pavlovska, C. P. Glover, J. B. Uney, D. Wraith, and N. J. Scolding, "Human mesenchymal stem cells abrogate experimental allergic encephalomyelitis after intraperitoneal injection, and with sparse CNS infiltration," Neuroscience Letters, vol. 448, no. 1, pp. 71-73, 2008.

[70] M. Chopp, X. H. Zhang, Y. Li et al., "Spinal cord injury in rat: treatment with bone marrow stromal cell transplantation," NeuroReport, vol. 11, no. 13, pp. 3001-3005, 2000.

[71] J. Lee, S. Kuroda, H. Shichinohe et al., "Migration and differentiation of nuclear fluorescence-labeled bone marrow stromal cells after transplantation into cerebral infarct and spinal cord injury in mice," Neuropathology, vol. 23, no. 3, pp. 169-180, 2003.

[72] J. Croitoru-Lamoury, K. R. Williams, F. M. J. Lamoury et al., "Neural transplantation of human MSC and NT2 cells in the twitcher mouse model," Cytotherapy, vol. 8, no. 5, pp. 445458, 2006.

[73] Y. Akiyama, C. Radtke, and J. D. Kocsis, "Remyelination of the rat spinal cord by transplantation of identified bone marrow stromal cells," Journal of Neuroscience, vol. 22, no. 15, pp. 6623-6630, 2002.

[74] Y. Akiyama, C. Radtke, O. Honmou, and J. D. Kocsis, "Remyelination of the spinal cord following intravenous delivery of bone marrow cells," Glia, vol. 39, no. 3, pp. 229236, 2002.

[75] M. Chopp and Y. Li, "Treatment of neural injury with marrow stromal cells," Lancet Neurology, vol. 1, no. 2, pp. 92100, 2002.

[76] A. Mahmood, D. Lu, M. Lu et al., "Treatment of traumatic brain injury in adult rats with intravenous administration of human bone marrow stromal cells," Neurosurgery, vol. 53, no. 3, pp. 697-703, 2003. 
[77] A. Mahmood, D. Lu, C. Qu, A. Coussev, and M. Chopp, "Human marrow stromal cell treatment provides longlasting benefit after traumatic brain injury in rats," Neurosurgery, vol. 57, no. 5, pp. 1026-1031, 2005.

[78] O. Y. Bang, J. S. Lee, P. H. Lee, and G. Lee, "Autologous mesenchymal stem cell transplantation in stroke patients," Annals of Neurology, vol. 57, no. 6, pp. 874-882, 2005.

[79] P. H. Lee, J. W. Kim, O. Y. Bang, Y. H. Ahn, I. S. Joo, and K. Huh, "Autologous mesenchymal stem cell therapy delays the progression of neurological deficits in patients with multiple system atrophy," Clinical Pharmacology and Therapeutics, vol. 83, no. 5, pp. 723-730, 2008.

[80] L. Mazzini, I. Ferrero, V. Luparello et al., "Mesenchymal stem cell transplantation in amyotrophic lateral sclerosis: a Phase I clinical trial," Experimental Neurology, vol. 223, no. 1, pp. 229-237, 2010.

[81] O. N. Koç, J. Day, M. Nieder, S. L. Gerson, H. M. Lazarus, and W. Krivit, "Allogeneic mesenchymal stem cell infusion for treatment of metachromatic leukodystrophy (MLD) and Hurler syndrome (MPS-IH)," Bone Marrow Transplantation, vol. 30, no. 4, pp. 215-222, 2002.

[82] N. Scolding, D. Marks, and C. Rice, "Autologous mesenchymal bone marrow stem cells: practical considerations," Journal of the Neurological Sciences, vol. 265, no. 1-2, pp. 111$115,2008$.

[83] A. Keating, "Mesenchymal stromal cells," Current Opinion in Hematology, vol. 13, no. 6, pp. 419-425, 2006.

[84] A. J. Friedenstein, I. I. Piatetzky-Shapiro, and K. V. Petrakova, "Osteogenesis in transplants of bone marrow cells," Journal of Embryology and Experimental Morphology, vol. 16, no. 3, pp. 381-390, 1966.

[85] M. F. Pittenger, A. M. Mackay, S. C. Beck et al., "Multilineage potential of adult human mesenchymal stem cells," Science, vol. 284, no. 5411, pp. 143-147, 1999.

[86] C. Campagnoli, I. A. G. Roberts, S. Kumar, P. R. Bennett, I. Bellantuono, and N. M. Fisk, "Identification of mesenchymal stem/progenitor cells in human first-trimester fetal blood, liver, and bone marrow," Blood, vol. 98, no. 8, pp. 2396-2402, 2001.

[87] A. Erices, P. Conget, and J. J. Minguell, "Mesenchymal progenitor cells in human umbilical cord blood," British Journal of Haematology, vol. 109, no. 1, pp. 235-242, 2000.

[88] D. J. Prockop, "Marrow stromal cells as stem cells for nonhematopoietic tissues," Science, vol. 276, no. 5309, pp. 71-74, 1997.

[89] N. J. Zvaifler, L. Marinova-Mutafchieva, G. Adams et al., "Mesenchymal precursor cells in the blood of normal individuals," Arthritis Research, vol. 2, no. 6, pp. 477-488, 2000.

[90] K. O’Donoghue, M. Choolani, J. Chan et al., "Identification of fetal mesenchymal stem cells in maternal blood: implications for non-invasive prenatal diagnosis," Molecular Human Reproduction, vol. 9, no. 7-8, pp. 497-502, 2003.

[91] O. K. Lee, T. K. Kuo, W. M. Chen, K. D. Lee, S. L. Hsieh, and T. $\mathrm{H}$. Chen, "Isolation of multipotent mesenchymal stem cells from umbilical cord blood," Blood, vol. 103, no. 5, pp. 16691675, 2004.

[92] D. Suva, G. Garavaglia, J. Menetrey et al., "Nonhematopoietic human bone marrow contains long-lasting, pluripotential mesenchymal stem cells," Journal of Cellular Physiology, vol. 198, no. 1, pp. 110-118, 2004.

[93] P. S. In't Anker, W. A. Noort, S. A. Scherjon et al., "Mesenchymal stem cells in human second-trimester bone marrow, liver, lung, and spleen exhibit a similar immunophenotype but a heterogeneous multilineage differentiation potential," Haematologica, vol. 88, no. 8, pp. 845-852, 2003.

[94] C. M. Digirolamo, D. Stokes, D. Colter, D. G. Phinney, R. Class, and D. J. Prockop, "Propagation and senescence of human marrow stromal cells in culture: a simple colonyforming assay identifies samples with the greatest potential to propagate and differentiate," British Journal of Haematology, vol. 107, no. 2, pp. 275-281, 1999.

[95] D. C. Colter, R. Class, C. M. DiGirolamo, and D. J. Prockop, "Rapid expansion of recycling stem cells in cultures of plasticadherent cells from human bone marrow," Proceedings of the National Academy of Sciences of the United States of America, vol. 97, no. 7, pp. 3213-3218, 2000.

[96] E. H. Javazon, D. C. Colter, E. J. Schwarz, and D. J. Prockop, "Rat marrow stromal cells are more sensitive to plating density and expand more rapidly from single-cell-derived colonies than human marrow stromal cells," Stem Cells, vol. 19, no. 3, pp. 219-225, 2001.

[97] S. E. Haynesworth, M. A. Baber, and A. I. Caplan, "Cell surface antigens on human marrow-derived mesenchymal cells are detected by monoclonal antibodies," Bone, vol. 13, no. 1, pp. 69-80, 1992.

[98] D. Woodbury, E. J. Schwarz, D. J. Prockop, and I. B. Black, "Adult rat and human bone marrow stromal cells differentiate into neurons," Journal of Neuroscience Research, vol. 61, no. 4, pp. 364-370, 2000.

[99] M. Reyes, T. Lund, T. Lenvik, D. Aguiar, L. Koodie, and C. M. Verfaillie, "Purification and ex vivo expansion of postnatal human marrow mesodermal progenitor cells," Blood, vol. 98, no. 9, pp. 2615-2625, 2001.

[100] G. C. Kopen, D. J. Prockop, and D. G. Phinney, "Marrow stromal cells migrate throughout forebrain and cerebellum, and they differentiate into astrocytes after injection into neonatal mouse brains," Proceedings of the National Academy of Sciences of the United States of America, vol. 96, no. 19, pp. 10711-10716, 1999.

[101] S. Wakitani, T. Saito, and A. I. Caplan, "Myogenic cells derived from rat bone marrow mesenchymal stem cells exposed to 5-azacytidine," Muscle and Nerve, vol. 18, no. 12, pp. 1417-1426, 1995.

[102] L.-R. Zhao, W.-M. Duan, M. Reyes, C. D. Keene, C. M. Verfaillie, and W. C. Low, "Human bone marrow stem cells exhibit neural phenotypes and ameliorate neurological deficits after grafting into the ischemic brain of rats," Experimental Neurology, vol. 174, no. 1, pp. 11-20, 2002.

[103] D. Woodbury, K. Reynolds, and I. B. Black, "Adult bone marrow stromal stem cells express germline, ectodermal, endodermal, and mesodermal genes prior to neurogenesis," Journal of Neuroscience Research, vol. 69, no. 6, pp. 908-917, 2002.

[104] N. Beyer Nardi and L. da Silva Meirelles, "Mesenchymal stem cells: isolation, in vitro expansion and characterization," Handbook of Experimental Pharmacology, no. 174, pp. 249282, 2006.

[105] A. M. Parr, C. H. Tator, and A. Keating, "Bone marrowderived mesenchymal stromal cells for the repair of central nervous system injury," Bone Marrow Transplantation, vol. 40, no. 7, pp. 609-619, 2007.

[106] A. Bartholomew, C. Sturgeon, M. Siatskas et al., "Mesenchymal stem cells suppress lymphocyte proliferation in vitro and prolong skin graft survival in vivo," Experimental Hematology, vol. 30, no. 1, pp. 42-48, 2002.

[107] S. Beyth, Z. Borovsky, D. Mevorach et al., "Human mesenchymal stem cells alter antigen-presenting cell maturation 
and induce T-cell unresponsiveness," Blood, vol. 105, no. 5, pp. 2214-2219, 2005.

[108] K. Le Blanc, C. Tammik, K. Rosendahl, E. Zetterberg, and O. Ringdén, "HLA expression and immunologic properties of differentiated and undifferentiated mesenchymal stem cells," Experimental Hematology, vol. 31, no. 10, pp. 890-896, 2003.

[109] B. Maitra, E. Szekely, K. Gjini et al., "Human mesenchymal stem cells support unrelated donor hematopoietic stem cells and suppress T-cell activation," Bone Marrow Transplantation, vol. 33, no. 6, pp. 597-604, 2004.

[110] S. Arnhold, H. Klein, F.-J. Klinz et al., "Human bone marrow stroma cells display certain neural characteristics and integrate in the subventricular compartment after injection into the liquor system," European Journal of Cell Biology, vol. 85, no. 6, pp. 551-565, 2006.

[111] M. Hokari, S. Kuroda, H. Shichinohe, S. Yano, K. Hida, and Y. Iwasaki, "Bone marrow stromal cells protect and repair damaged neurons through multiple mechanisms," Journal of Neuroscience Research, vol. 86, no. 5, pp. 1024-1035, 2008.

[112] L. Crigler, R. C. Robey, A. Asawachaicharn, D. Gaupp, and D. G. Phinney, "Human mesenchymal stem cell subpopulations express a variety of neuro-regulatory molecules and promote neuronal cell survival and neuritogenesis," Experimental Neurology, vol. 198, no. 1, pp. 54-64, 2006.

[113] D. V. Ratnam, D. D. Ankola, V. Bhardwaj, D. K. Sahana, and M. N. V. R. Kumar, "Role of antioxidants in prophylaxis and therapy: a pharmaceutical perspective," Journal of Controlled Release, vol. 113, no. 3, pp. 189-207, 2006.

[114] M. Christofidou-Solomidou and V. R. Muzykantov, "Antioxidant strategies in respiratory medicine," Treatments in Respiratory Medicine, vol. 5, no. 1, pp. 47-78, 2006.

[115] A. G. Estévez, N. Spear, S. M. Manuel et al., "Nitric oxide and superoxide contribute to motor neuron apoptosis induced by trophic factor deprivation," Journal of Neuroscience, vol. 18, no. 3, pp. 923-931, 1998.

[116] J. Y. Wang, A. Y. C. Shum, Y. J. Ho, and J. Y. Wang, "Oxidative neurotoxicity in rat cerebral cortex neurons: synergistic effects of $\mathrm{H} 2 \mathrm{O} 2$ and $\mathrm{NO}$ on apoptosis involving activation of p38 mitogen-activated protein kinase and caspase-3," Journal of Neuroscience Research, vol. 72, no. 4, pp. 508-519, 2003.

[117] D. R. Kaplan and F. D. Miller, "Neurotrophin signal transduction in the nervous system," Current Opinion in Neurobiology, vol. 10, no. 3, pp. 381-391, 2000.

[118] J. L. Goldberg and B. A. Barres, "The relationship between neuronal survival and regeneration," Annual Review of Neuroscience, vol. 23, pp. 579-612, 2000.

[119] E. Nozik-Grayck, H. B. Suliman, and C. A. Piantadosi, "Extracellular superoxide dismutase," International Journal of Biochemistry and Cell Biology, vol. 37, no. 12, pp. 2466-2471, 2005.

[120] H. E. Lob, P. J. Marvar, T. J. Guzik et al., "Induction of hypertension and peripheral inflammation by reduction of extracellular superoxide dismutase in the central nervous system," Hypertension, vol. 55, no. 2, pp. 277-283, 2010.

[121] J. P. Laurila, L. E. Laatikainen, M. D. Castellone, and M. O. Laukkanen, "SOD3 reduces inflammatory cell migration by regulating adhesion molecule and cytokine expression," PLoS One, vol. 4, no. 6, Article ID e5786, 2009.

[122] R. J. Folz, A. M. Abushamaa, and H. B. Suliman, "Extracellular superoxide dismutase in the airways of transgenic mice reduces inflammation and attenuates lung toxicity following hyperoxia," Journal of Clinical Investigation, vol. 103, no. 7, pp. 1055-1066, 1999.
[123] R. P. Bowler, M. Nicks, K. Tran et al., "Extracellular superoxide dismutase attenuates lipopolysaccharide-induced neutrophilic inflammation," American Journal of Respiratory Cell and Molecular Biology, vol. 31, no. 4, pp. 432-439, 2004.

[124] F. Gao, J. R. Koenitzer, J. M. Tobolewski et al., "Extracellular superoxide dismutase inhibits inflammation by preventing oxidative fragmentation of hyaluronan," Journal of Biological Chemistry, vol. 283, no. 10, pp. 6058-6066, 2008.

[125] H. Y. Ha, Y. Kim, Z. Y. Ryoo, and T. Y. Kim, "Inhibition of the TPA-induced cutaneous inflammation and hyperplasia by EC-SOD," Biochemical and Biophysical Research Communications, vol. 348, no. 2, pp. 450-458, 2006.

[126] V. Lubrano, P. Di Cecco, and G. C. Zucchelli, "Role of superoxide dismutase in vascular inflammation and in coronary artery disease," Clinical and Experimental Medicine, vol. 6, no. 2, pp. 84-88, 2006.

[127] Z. N. Rabbani, M. S. Anscher, R. J. Folz et al., "Overexpression of extracellular superoxide dismutase reduces acute radiation induced lung toxicity," BMC Cancer, vol. 5, article 59, 2005.

[128] J. Ueda, M. E. Starr, H. Takahashi et al., "Decreased pulmonary extracellular superoxide dismutase during systemic inflammation," Free Radical Biology and Medicine, vol. 45, no. 6, pp. 897-904, 2008.

[129] G. Stoll, S. Jander, and M. Schroeter, "Cytokines in CNS disorders: neurotoxicity versus neuroprotection," Journal of Neural Transmission, Supplement, no. 59, pp. 81-89, 2000.

[130] C. F. Nathan, H. W. Murray, M. E. Wiebe, and B. Y. Rubin, "Identification of interferon- $\gamma$ as the lymphokine that activates human macrophage oxidative metabolism and antimicrobial activity," Journal of Experimental Medicine, vol. 158, no. 3, pp. 670-689, 1983.

[131] R. L. Berkow, D. Wang, J. W. Larrick, R. W. Dodson, and T. H. Howard, "Enhancement of neutrophil superoxide production by preincubation with recombinant human tumor necrosis factor," Journal of Immunology, vol. 139, no. 11, pp. 3783-3791, 1987.

[132] T. Matsubara and M. Ziff, "Increased superoxide anion release from human endothelial cells in response to cytokines," Journal of Immunology, vol. 137, no. 10, pp. 32953298, 1986.

[133] M. L. Tiku, J. B. Liesch, and F. M. Robertson, "Production of hydrogen peroxide by rabbit articular chondrocytes. Enhancement by cytokines," Journal of Immunology, vol. 145, no. 2, pp. 690-696, 1990.

[134] I. Kassis, N. Grigoriadis, B. Gowda-Kurkalli et al., "Neuroprotection and immunomodulation with mesenchymal stem cells in chronic experimental autoimmune encephalomyelitis," Archives of Neurology, vol. 65, no. 6, pp. 753-761, 2008.

[135] E. Zappia, S. Casazza, E. Pedemonte et al., "Mesenchymal stem cells ameliorate experimental autoimmune encephalomyelitis inducing T-cell anergy," Blood, vol. 106, no. 5, pp. 1755-1761, 2005.

[136] E. Gerdoni, B. Gallo, S. Casazza et al., "Mesenchymal stem cells effectively modulate pathogenic immune response in experimental autoimmune encephalomyelitis," Annals of Neurology, vol. 61, no. 3, pp. 219-227, 2007.

[137] L. Bai, D. P. Lennon, V. Eaton et al., "Human bone marrowderived mesenchymal stem cells induce Th2-polarized immune response and promote endogenous repair in animal models of multiple sclerosis," Glia, vol. 57, no. 11, pp. 11921203, 2009.

[138] E. N. Benveniste and D. J. Benos, "TNF- $\alpha$ - and IFN- $\gamma$ mediated signal transduction pathways: effects on glial cell 
gene expression and function," FASEB Journal, vol. 9, no. 15, pp. 1577-1584, 1995.

[139] M. B. Abrams, C. Dominguez, K. Pernold et al., "Multipotent mesenchymal stromal cells attenuate chronic inflammation and injury-induced sensitivity to mechanical stimuli in experimental spinal cord injury," Restorative Neurology and Neuroscience, vol. 27, no. 4, pp. 307-321, 2009.

[140] Y.-J. Kim, H.-J. Park, G. Lee et al., "Neuroprotective effects of human mesenchymal stem cells on dopaminergic neurons through anti-inflammatory action," Glia, vol. 57, no. 1, pp. 13-23, 2009.

[141] H. J. Park, P. H. Lee, Y. W. Ahn et al., "Neuroprotective effect of nicotine on dopaminergic neurons by anti-inflammatory action," European Journal of Neuroscience, vol. 26, no. 1, pp. 79-89, 2007.

[142] A. Vercelli, O. M. Mereuta, D. Garbossa et al., "Human mesenchymal stem cell transplantation extends survival, improves motor performance and decreases neuroinflammation in mouse model of amyotrophic lateral sclerosis," Neurobiology of Disease, vol. 31, no. 3, pp. 395-405, 2008. 


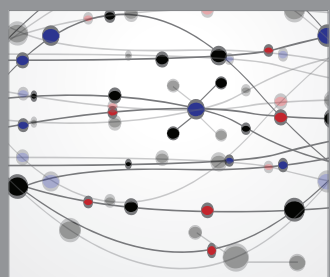

The Scientific World Journal
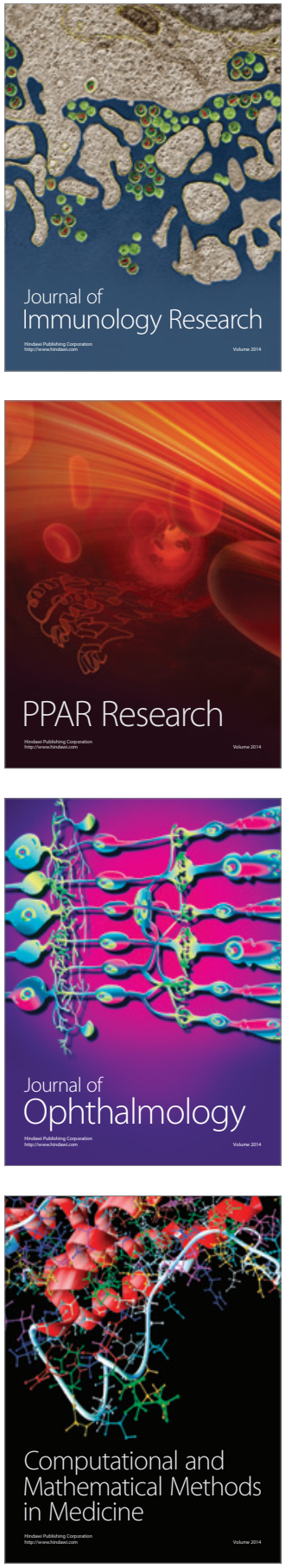

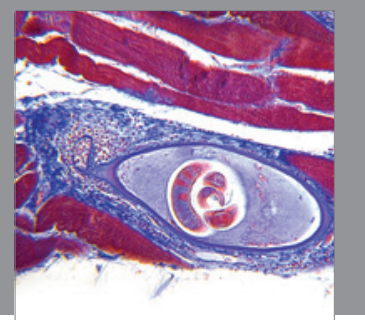

Gastroenterology

Research and Practice
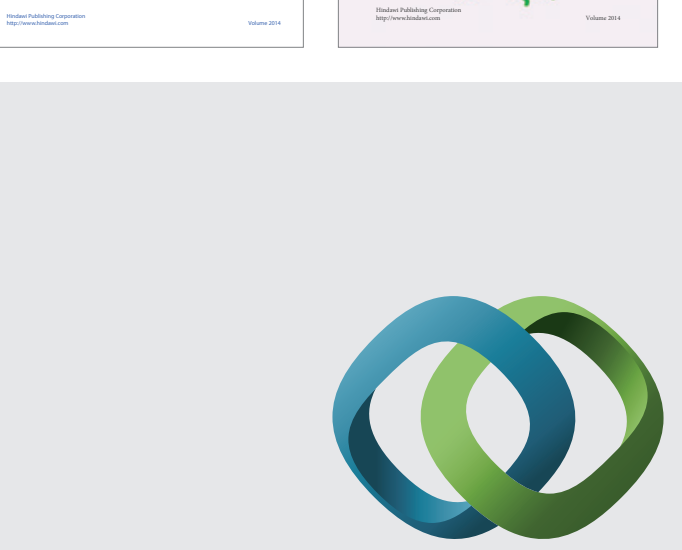

\section{Hindawi}

Submit your manuscripts at

http://www.hindawi.com
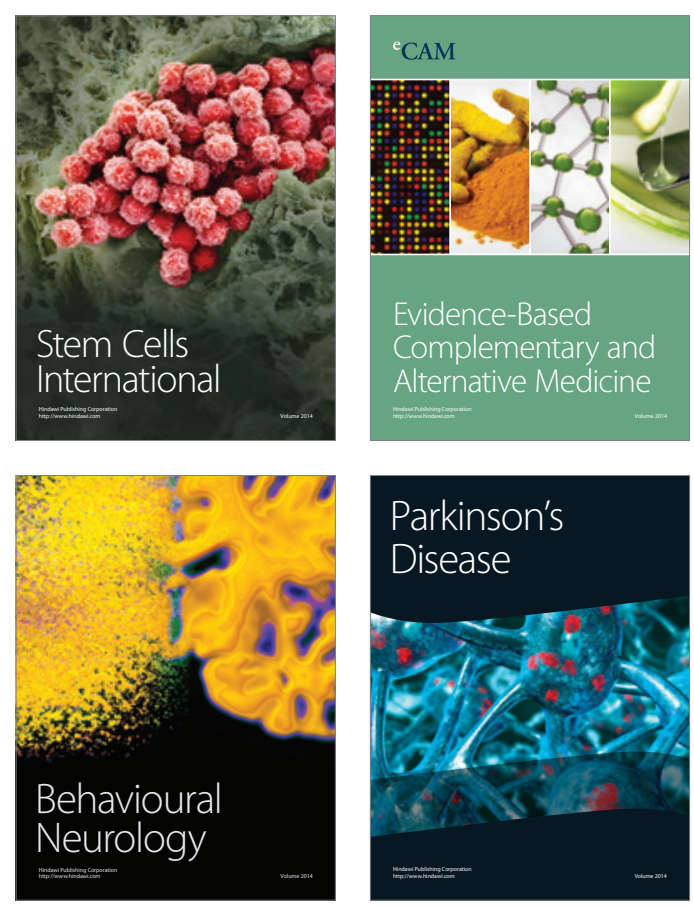

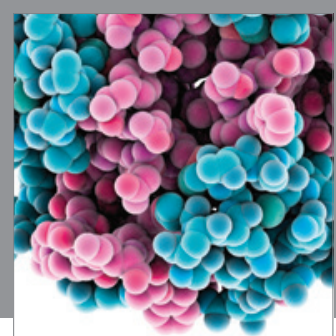

Journal of
Diabetes Research

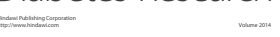

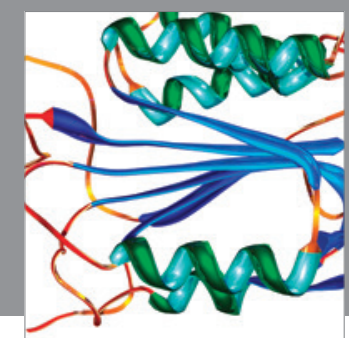

Disease Markers
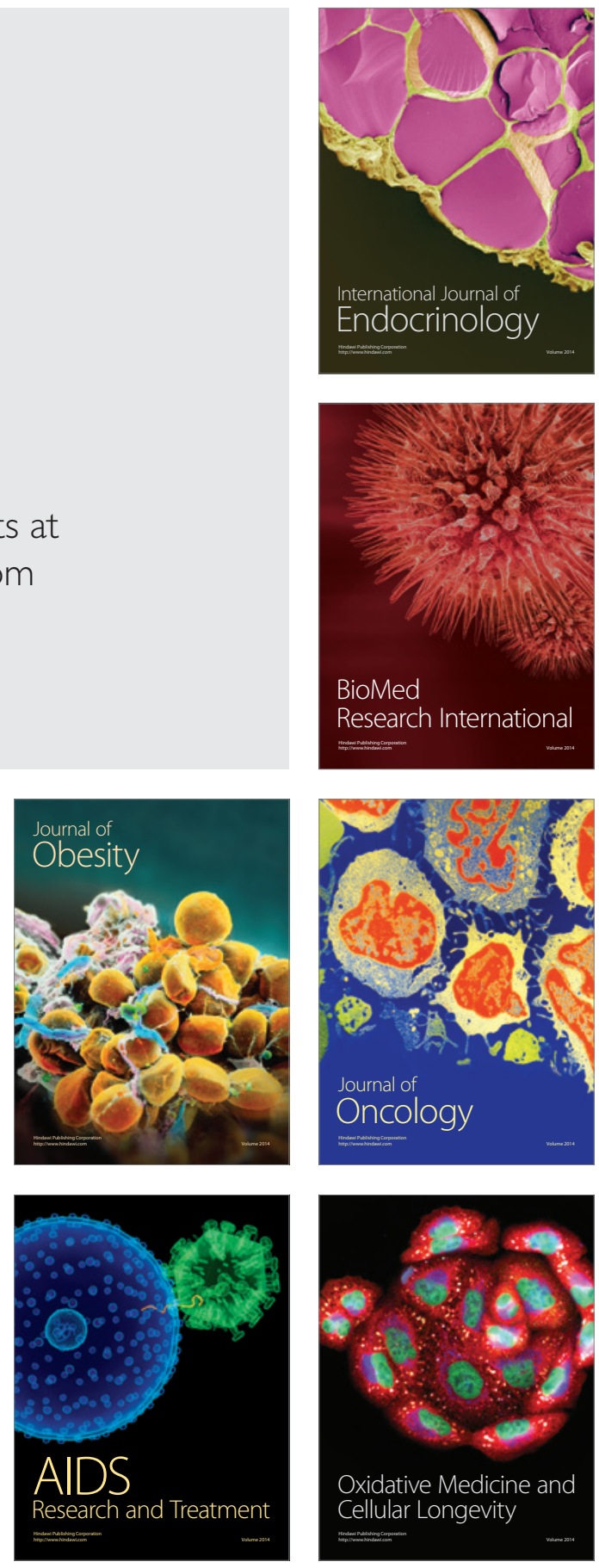